\title{
The Guatemalan social pyramid in the XXI century
}

\author{
Guillermo Diaz \\ Universidad Rafael Landívar, Guatemala \\ Email: godiaz@url.edu.gt
}

\begin{abstract}
This paper describes the composition of the Guatemalan social pyramid in the 21 st century, built from a class scheme elaborated based on occupational categories and a social stratification carried out according to income and education. The data were obtained from population censuses and employment and income surveys, from the years 2002 and 2018. The results show that the Guatemalan social pyramid is of a triangular type, with a broad working-class base, according to the class scheme, or very poor low stratum, according to socioeconomic stratification. They also show that the base remained stable in the two years in comparison, which is interpreted as an indicator of a society with few opportunities for social mobility.
\end{abstract}

Keywords: social pyramid, social stratification, class structure, social mobility, social classes. 


\section{Introduction}

In the first two decades of the 21st century, the Guatemalan economy grew at an average annual rate of $3.5 \%$. A priori, it is to be expected that such economic growth will benefit the population and promote changes in the social structure. Some economic and social indicators point in this direction. In the first case, per capita income increased from US \$1,665 to US \$ 4,472 between 2000 and 2018 (World Bank, 2019). In the second, the net rate of basic education, which includes 9 years of study, rose from $30 \%$ to $42 \%$ and that of secondary education, which includes 2 or 3 more years, increased eight percentage points, to $24 \%$ (Ministry of Education, 2019).

However, the evolution of the poverty rate in said period shows that economic growth did not benefit the majority of the Guatemalan population, because it first fell from $56 \%$ to $51 \%$ between 2000 and 2006, and then increased to 59\% to 2014. Guatemala is the fifth country with the highest poverty rate in Latin America (World Bank, 2019). The evolution and persistence of a high poverty rate in Guatemala suggests that the country faces the problem of a poverty trap, a term that refers to the vicious circle in which current poverty is the cause of future poverty (Azariadis and Stachuski, 2005). The concentration of income affects the high rate of poverty. The Gini index, with a value of 0.48 , places Guatemala as one of the countries with the highest concentration of income in the world (World Bank, 2019), which limits opportunities to overcome poverty. The experience of Latin America in the first two decades of the 21 st century shows that the countries that reduced their Gini index also decreased their poverty rate (Díaz, 2019).

The persistence of high values in the indicators of poverty and income concentration, in sociological terms, leads us to think about the existence of a rigid or closed social structure in Guatemalan society. In fact, Guatemala was ranked among the countries with the lowest social mobility, in position 75 out of 82 , in the 2020 Global Social Mobility Report (World Economic Forum, 2020).

Studies on stratification and social mobility in Guatemala in the first two decades of the 21 st century are scarce, despite the fact that this topic, together with that of social stratification, has been taken up in Latin America by sociological research. At the Latin American level, we can cite, among others, those prepared by Portes and Hoffman (2003) and Marinho and Quiroz (2018). For Mexico, the studies of Cortés and Escobar (2005) and Serrano and Torche (2010), those of Kessler and Espinoza (2003) and Dalle (2012), for Argentina, and those of 
Sembler (2006), Ezpinoza, Bazoret and Méndez (2013) Pérez (2018), for Chile. In Guatemala, the investigations of Díaz (2012) and Ferreira, Messina, Rigolini, López, Lugo and Vakis (2013) can be cited.

This research is motivated by the desire to know how open or closed the class structure was in Guatemalan society, in response to the changes registered in the first two decades of the 21 st century. It is interesting to know how much social mobility did or did not produce economic growth during the first two decades of the 21 st century. Also, know the changes in the occupational and class structure.

The methodological approach to the subjects under study is carried out through the construction of the class structure, based on data from the occupations reported in the 2002 and 2018 population censuses. Data from employment and income surveys of those groups are also used. years to build a social stratification scheme, based on income and education indicators.

\section{Literature review}

Social classes and social stratification are two of the most studied topics in sociology, both from a theoretical and an empirical perspective. Consequently, the existing literature on the matter is extensive. In this section an outline of the theories, approaches and schemes reviewed and selected for considering that they contribute to the study carried out is made.

The sociological analysis of social classes begins with Marx (Marx, 1973), who defines social classes from their relationship with the ownership of the means of production, from which he raises a relationship of conflict between two main classes, the capitalists (owners) and workers (non-owners). According to this theory, social classes have manifested themselves in history by their antagonistic position, expressed in class struggle (Marx and Engels, 1970). The Marxist theory of social classes was joined by numerous authors, including Dahrendorf (1966), Poulantzas (1977), Touraine (1995) and Wright (1999), who reinterpreted Marx's initial ideas to complete their theory, because said author died before he could. In fact, Marx used the term class in various and even contradictory ways in his various works (Kerbo, 2003).

Of the aforementioned authors, Touraine (1995) with his approach of two classes, one superior and the other popular, take relevance for this research work, as well as Wright (1999), who is the most influential contemporary Marxist theorist, due to his definition of the social classes from the relationship of authority and job qualifications, in addition to the 
relationship with ownership of the means of production. Wright approaches authority as a dimension of class relations in capitalism, within which managers and supervisors are those who exercise control of the means of production by delegation of the capitalists. From that account, managers and supervisors distinguish them from the workers because they participate in the distribution of the economic surplus. Qualification is an element of differentiation between workers in capitalism. At the author's discretion, the rating gives rise to strata within the inequality structure. From the elements indicated, Wright drew up the matrix presented in Table 1, which links forms of appropriation and domination according to capitalist relations or the production of small commodities.

Wright's theory identifies class relations with the unequal distribution of rights over the means of production. Based on this conception, he defines the class structure as "the total sum of the class relations in a given unit of analysis... we can speak of the class structure of a company, of a city, of a country... (Wright, 1999: 7). The relevance of this concept in the author's analysis is that "the class structure deals with the structure of social relations in which individuals (or, in some cases, families) determine their class interests.... the class structure defines the set of empty places or positions occupied by individuals or families "(Wright, 1985: 10). An important element of this theory for this research is that the class structure provides a mechanism to describe social changes over time.

Table 1. Wright class scheme

\begin{tabular}{|c|c|c|c|c|}
\hline \multirow[b]{2}{*}{ Class } & \multicolumn{2}{|c|}{ Capitalist relations } & \multicolumn{2}{|c|}{$\begin{array}{l}\text { Relations of production of small } \\
\text { goods }\end{array}$} \\
\hline & Appropriation & Domination & Appropriation & Domination \\
\hline Bourgoeisie & + & + & & \\
\hline Senior managers & $+/-$ & $+/-$ & & \\
\hline Low supervisors & - & $+/-$ & & \\
\hline Workers & - & - & & \\
\hline Petty bourgoeisie & & & + & + \\
\hline Semi-autonomous employees & - & - & - & + \\
\hline Samll employers & + & + & + & + \\
\hline
\end{tabular}

Source: Wright, 1997. 
The other classic author of the analysis of social classes is Max Weber, who, in terms of Kerbo (2003), presents an alternative paradigm of conflict, which includes, in addition to the economic, political and social factors, among others, as a cause of conflict. conflict. For Weber, social classes are defined based on unequal access to scarce and socially valued resources, especially property, wealth and market position, determined by training. Access to such resources means that members of a social class have similar life opportunities. From these factors, Weber identified four social classes: the workers, without property or training; the petty bourgeoisie, with property but little training; white-collar technical officers and employees, who are trained but not owned; and the bourgeoisie, who have property and training (Requena, Salazar and Radl, 2013). The following authors Lenski (1969), Parkin (1978) and Erikson and Goldthorpe (1993) have relevance to this theory. Of Lenski's theory the concepts of power, privilege and prestige are of interest. Power is defined by said author as the possibility of appropriating all or most of the economic surplus, while privilege is the possession of said surplus and prestige is something that derives from the previous two. For Lenski, social classes are groups of people who have similarities in terms of power, prestige and privilege, so the class structure is based on the share of power of each class.

For his part, Parkin (1978), considers that social classes are formed from the occupational structure. He calls this "the master wall of the class hierarchy." Based on this approach, the aforementioned author identifies six occupational categories that give rise to unequal remuneration in current capitalism, which are: Professionals, technicians and executives; Medium grade and administrative technicians; Small employees; Skilled manual workers; Semi-skilled manual workers; and Unskilled manual workers. For Parkin, qualifications and property are the main factors of social exclusion in capitalist society. On this issue, the concept of "excluding social closure" is key, which he uses to refer to the process by which a social group privileges its position at the expense of other groups.

Erikson and Goldthorpe (1993), based on Weber's approach to power and status, elaborate a class scheme based on occupation and the status associated with it, which allows them to group occupational categories of individuals with similar income levels and working conditions (Atria, 2004). His scheme takes into consideration the position of the individual within the production process, thereby incorporating the authority factor. Erikson and Goldthorpe's basic scheme is based on three class positions. In a later version, prepared together with Portocarero, the number of classes was increased to 11 (Marhino and Quiroz, 2018). Table 2 presents both schemes. 
Marhino and Quiroz (2018) applied both schemes for the Central American countries, Panama, the Dominican Republic and Mexico. In the case of Guatemala, a country that is interesting for being the center of this research, the service class represented $8.3 \%$ of the population consulted in the 2017 national employment and income survey. The non-manual class constituted $48.7 \%$ and the class $43 \%$ hard-working. The authors also developed a social stratification scheme based on two dimensions: education and income. In both cases, they used quartiles to develop the double-entry classification matrix. In education, the low quartile comprised up to 6 years of study and the high quartile more than 12 years of schooling.

Table 2 . Erikson, Goldthorpe y Portocarrero class scheme

\begin{tabular}{|c|c|}
\hline 3 classes & 11 classes \\
\hline \multirow[b]{2}{*}{ Clase de servicio } & I. Large owners, senior managers and professionals \\
\hline & II. Senior technicians and middle managers \\
\hline \multirow{4}{*}{$\begin{array}{l}\text { Clase no manual o } \\
\text { intermedia }\end{array}$} & III a. Office workers \\
\hline & III b. Trade assistants \\
\hline & IV a. Small employers \\
\hline & IV b. Freelancers without employees \\
\hline \multirow{5}{*}{ Clase trabajadora } & V. Lower technicians and manual supervisors \\
\hline & VI. Skilled and semi-skilled manual wage earners \\
\hline & VII a. Low-skilled manual wage earners \\
\hline & IV c. Small agricultural owners \\
\hline & VII b. Agricultural wage earners \\
\hline
\end{tabular}

Source: Marhino and Quiroz, 2018.

Based on the approaches of Marx Weber and Parkin and the schemes of Wright and Erickson Goldthorpe and Portocarero, a class scheme based on three dimensions is presented: ownership of the means of production, authority and qualification. Additionally, the relationship they have in the labor market is considered, such as employers, self-employed workers and employees or salaried workers.

The proposed scheme raises three main classes: owner, intermediate and worker. Inside each one there are class positions, which are also called occupational class in this work, because they are based on the work occupation. The positions are integrated from the property with the means of production, the occupation they have and their connection in the labor market. 
The latter applies especially to the working class that is made up of salaried and independent workers or the self-employed. Table 3 presents the scheme that is proposed to analyze the class structure of Guatemala and its changes between 2002 and 2018.

Table 3. Social class scheme for Guatemala

\begin{tabular}{|c|c|c|c|c|}
\hline Class & Property & Authority & Qualification & $\begin{array}{l}\text { Relationship in the labor } \\
\text { market }\end{array}$ \\
\hline \multicolumn{5}{|l|}{ Owner class } \\
\hline Capitalist & + & + & $+/-$ & Employers \\
\hline Small entrepreneurs & + & + & $++/-$ & On their own \\
\hline \multicolumn{5}{|l|}{ Intermediate class } \\
\hline Manager and directores & - & + & + & Employees/Self employed \\
\hline Professionals & - & $+/-$ & + & Employees/Self employeds \\
\hline $\begin{array}{l}\text { Techinical and administrative } \\
\text { employees }\end{array}$ & - & $+/-$ & + & Employees/Self employed \\
\hline \multicolumn{5}{|l|}{ Working class } \\
\hline \multicolumn{5}{|l|}{ No manual } \\
\hline Employees & - & - & + & Employees \\
\hline Independent & - & - & + & On their own \\
\hline \multicolumn{5}{|l|}{ Manual } \\
\hline Employees & - & - & - & Employees \\
\hline Independent & - & - & - & On their own \\
\hline
\end{tabular}

Source: Owen elaboration.

\section{Class and stratification scheme}

The proposed scheme takes into account the dichotomy of owners and non-owners of means of production, which in a country like Guatemala means rich and poor. It also incorporates the contradictory condition of those who are located between both extremes, since although they do not have the means of production they have authority, to a greater or lesser extent, and qualification obtained, preferably, through academic credentials. At the same time, it allows the owner class to distinguish between capitalists and small entrepreneurs, based on their relationship in the labor market. Likewise, it makes it possible to distinguish between 
the working class, based on their relationship in the labor market and the qualification of their work, among those who occupy a greater or lesser position.

In addition to the previous scheme, a stratification scheme is also presented based on the one proposed by Marhino and Quiroz (2018), which is based on Bourdieu's (2001) notions of cultural capital and economic capital. The adaptation of this scheme is carried out because, in the case of Guatemala, it was found that the variables education and income are correlated with the work occupation, as stated by the authors. Table 4 presents the stratification matrix proposed in this research.

Table 4. Guatemala's social strata according to education and income

\begin{tabular}{|l|l|l|l|l|l|}
\hline Education/income & Quintile 1 & Quintile 2 & Quintile 3 & Quintile 4 & Quintile 5 \\
\hline $\begin{array}{l}\text { Without education or with } \\
\text { primary school, from 1 to } \\
6\end{array}$ & Low very poor & Low very poor & Low very poor & Low poor & Medium high \\
\hline $\begin{array}{l}\text { Secondary, 7 to 12 years } \\
\text { old }\end{array}$ & Low poor & Low poor & Medium low & Medium high & Medium high \\
\hline $\begin{array}{l}\text { Tertiary, more than 12 } \\
\text { years }\end{array}$ & Loow poor & Midum low & Medium low & High & High \\
\hline
\end{tabular}

Source: Own elaboration, based on Marhino and Quiroz, 2018.

As can be seen, the matrix or stratification scheme comprises the low, medium and high strata. The first two are subdivided into two, in order to differentiate the heterogeneity of their integration, with regard to the possession of cultural and economic capital, represented by education and monthly income. The very poor lower stratum pretends to represent the population in extreme poverty in the country, which lacks or has little education and very low incomes. The poor lower stratum tries to represent the population living in poverty, most of whom have primary education or more and low income. The middle stratum is divided into medium-low and medium-high. The first is made up of people who have secondary to tertiary education and high income. The upper stratum comprises those with tertiary education and the highest income.

\section{Data}

The data for the elaboration of the class scheme were obtained from the population census carried out in the years 2002 and 2018 (INE, 2003 and 2019). The universe was 3,463,397 and 5,048,234, respectively. Single-digit occupation information was obtained from each 
census, according to the uniform international classification of occupations, which was located in a double-entry matrix in the rows. In the columns, the variable occupational category was located, which divides the employed population according to whether it is employer, self-employed worker, or public or private employee. Likewise, it incorporates the categories of unpaid domestic and family employee, which represent occupations in conditions of labor vulnerability.

The employer category was classified as an owner class and divided into capitalists and small entrepreneurs, according to the percentages of small, medium and large companies reported in the national business directories (Banco de Guatemala, 2002 and 2013). The intermediate class was constituted by the occupations of managers, professionals and technicians and office workers (classifications 1, 2, 3 and 4). From the total for each occupation, the number of employers or employers was subtracted. The working class was integrated with the occupations of vendors, farmers, workers and unclassified (classifications 5, 6, 7, 8 and 9), dividing it into salaried and independent or self-employed, according to the occupational category indicated in the column of the matrix. In turn, it was classified between non-manual and manual. The first ones constituted by the classification 5 and the second by the classifications $6,7,8$ and 9 .

The data for the elaboration of the social strata were obtained from the national employment and income surveys (INE, 2003 and 2019), which provide information on the level of education and income of the interested persons. The size of the selected subsample for the 2002 national survey was 2,316 and 4,459 for the 2018 survey. As already mentioned, in the double-entry matrix, the primary, secondary and tertiary educational levels were located on the side of the rows and income quintiles on the column side. The total of people located in each box were classified according to the corresponding stratum.

\section{Changes in the Guatemalan social pyramid}

The class scheme developed, contained in Table 5, reveals that in 2002 the Guatemalan social structure was of the classic pyramidal type. The base was constituted by a broad working class, which represented $78.8 \%$ of the employed population or 2.7 million inhabitants. The foundation of this base were independent workers followed by salaried workers, who were $41.2 \%$ and $37.6 \%$, respectively. From another perspective, it is observed that the base were 
also manual workers, who constituted $69.4 \%$, of which a little more than half were independent or self-employed.

The intermediate class represented $12.6 \%$ of the population, equivalent to almost 437,000 people. Most of the intermediate class was made up of people who worked as technicians and administrative personnel, whose number was around 293,000, equal to $8.4 \%$ of the employed population. Professional and managerial and directive class positions were small, each representing almost $2 \%$ of the employed population.

The owner class was made up mostly of small businessmen, whose number in 2002 was 268,509 , equivalent to $7.8 \%$ of the employed persons. The capitalists or employers was a minimum percentage, of almost one percent, which numbered around 30,000 people. In total, the owner class was a little less than $9 \%$.

The existing situation in 2002 remained the same in 2018 at the base of the Guatemalan social pyramid, which makes it possible to raise the idea of a static society in that part of the social structure. In effect, the working class remained at 78\%, showing in 2018 a reduction of almost half a percentage point compared to 2002, but in absolute terms it increased to 3.9 million people. The main changes occurred within the working class, with an increase in the fraction of the independent working class, in an amount similar to the reduction in the salaried working class, which allows us to infer that there was a downward process of absolute social mobility. The number of self-employed workers increased to 2.2 million in 2018, against 1.4 million in 2002.

The intermediate class in 2018 registered an increase compared to 2002, but it is interpreted that it was also the result of a downward process of absolute social mobility of the owner class. The increase in the intermediate class occurred in the professional class fraction. This as a result of the massification of university education. The number of college graduates more than doubled between 2010 and 2015, from almost 15,000 to around 35,000 (Díaz, 2019). The fraction of the professional intermediate class totaled 365,757 in 2018 against almost 82,000 in 2002. In 2018 the intermediate class represented $17.4 \%$ of the employed population.

In 2018, the owner class was lower than in 2002, both in absolute and relative terms. In the first case, the number dropped from 298,343 to 220,712, respectively. The reduction occurred in small entrepreneurs, whose number decreased from 268,509 in 2002 to $187,605$. 
Consequently, the participation of this class fraction among the employed population was reduced by four percentage points.

The composition of the Guatemalan social pyramid for 2018, which is similar to that of 2002, is illustrated in graph 1. It can be seen in it the width of the steps of the base, constituted by the working class, and the narrowness of the rungs of the fractions of the intermediate class, as well as of the top formed by the owning class.

\section{Graph 1}

Source: Own elaboration based on table 5.

To better explain the changes in the class structure of Guatemala, the class structure is analyzed at the urban and rural geographical level, considering that the information from the 2018 population census revealed that the country is experiencing a process of urbanization. Consequently, it is interesting to know where there were major changes in the class structure and what was its configuration in urban and rural areas. Additionally, in the urban area, the class structure of the country's capital is analyzed, as it is the area with the greatest economic and social dynamism.

When comparing the urban and rural class scheme, the first thing that is observed, in table 6 , is that the intermediate class is more incipient in the rural area, which in graphic terms means that its pyramid is wider at the base and less thin in the middle part than that of the urban area. The rural social pyramid is shaped like an inverse cup, while that of the urban area is triangular. In this, the intermediate class has greater weight or importance than at the country level.

Table 6

Guatemala class scheme, according to geographic location.

Years 2002 and 2018

\begin{tabular}{|l|l|l|l|l|}
\hline Social classes & Urban & \multicolumn{2}{l|}{ Rural } \\
\cline { 2 - 5 } & 2002 & 2018 & 2002 & 2018 \\
\hline Owner class & & & & \\
\hline Capitalists & $\mathbf{7 . 9 \%}$ & $\mathbf{4 . 7 \%}$ & $\mathbf{9 . 4 \%}$ & $\mathbf{3 . 9 \%}$ \\
\hline Small entrepreneurs & $0.8 \%$ & $0.7 \%$ & $0.9 \%$ & $0.6 \%$ \\
\hline Intermediat class & $7.1 \%$ & $4.0 \%$ & $8.4 \%$ & $3.3 \%$ \\
\hline
\end{tabular}




\begin{tabular}{|l|l|l|l|l|}
\hline Managers and executives & $3.0 \%$ & $1.8 \%$ & $0.4 \%$ \\
\hline Professionals & $4.3 \%$ & $9.7 \%$ & $0.3 \%$ & $3.1 \%$ \\
\hline Technicians and administrative staff & $14.3 \%$ & $12.5 \%$ & $1.9 \%$ & $3.0 \%$ \\
\hline Working class & $\mathbf{7 0 . 5 \%}$ & $\mathbf{7 1 . 3 \%}$ & $\mathbf{8 8 . 1 \%}$ & $\mathbf{8 9 . 7 \%}$ \\
\hline Employees & $41.3 \%$ & $34.0 \%$ & $33.4 \%$ & $34.6 \%$ \\
\hline No manuals & $8.9 \%$ & $11.0 \%$ & $2.9 \%$ & $6.3 \%$ \\
\hline Manuals & $32.3 \%$ & $23.0 \%$ & $30.5 \%$ & $28.3 \%$ \\
\hline Independent & $29.3 \%$ & $37.3 \%$ & $54.6 \%$ & $55.1 \%$ \\
\hline No manuals & $4.7 \%$ & $9.3 \%$ & $1.7 \%$ & $4.6 \%$ \\
\hline Manuals & $24.6 \%$ & $28.0 \%$ & $52.9 \%$ & $50.5 \%$ \\
\hline Total & $100.0 \%$ & $100.0 \%$ & $100.0 \%$ & $100.0 \%$ \\
\hline
\end{tabular}

Source: Own elaboration

In both geographic areas, the pattern of changes is similar to that described at the country level, with regard to the reduction of the owner class and increase of the intermediate class between 2002 and 2018. In the working class in both areas there is a small increase, of almost one percentage point in urban areas and close to two percentage points in rural areas. In urban areas, the working class represented around $70 \%$ of the employed population in the two years analyzed, while in rural areas it was almost $90 \%$. In both, manual workers were the majority in 2002 and 2018, but more so in rural areas, characteristic of the trait of agricultural society that Guatemala still has, particularly with regard to self-employment as a farmer. In the intermediate class, the most important class fraction in both geographic areas is that of technicians and administrative personnel.

In 2002, according to the weight of the population, the working class was more rural in nature, with a $53 \%$ share of the total of this class in the country. This situation changed in 2018 in favor of the urban population, with $57 \%$. In absolute terms, the rural working class rose from 1.4 million in 2002, against 1.2 million of the urban, while in 2018 it was 1.7 against 2.2 million, respectively. The size of 123,122 in 2018 illustrates the incipient state of development of the rural middle class.

The changes in the class structure of Guatemala City between 2002 and 2018 differ from the pattern evidenced at the country level and according to urban and rural geographical areas, as shown in Table 7. The main change that occurred in the period analyzed was the decrease in 
the participation of the working class, offset by an increase in the intermediate class, which is interpreted as an upward process of absolute mobility.

Table 7

Guatemala city class scheme.

Years: 2002 and 2018

\begin{tabular}{|c|c|c|}
\hline Social classes & 2002 & 2018 \\
\hline Owner class & $8.4 \%$ & $4.2 \%$ \\
\hline Capitalists & $0.8 \%$ & $0.6 \%$ \\
\hline Smalls entrepreneurs & $7.6 \%$ & $3.6 \%$ \\
\hline Intermediate class & $23.2 \%$ & $38.9 \%$ \\
\hline Managers and executives & $3.5 \%$ & $3.3 \%$ \\
\hline Professionals & $4.8 \%$ & $14.1 \%$ \\
\hline Technicians and administrative staff & $14.8 \%$ & $21.5 \%$ \\
\hline Working class & $68.4 \%$ & $57.0 \%$ \\
\hline Employess & $37.7 \%$ & $28.3 \%$ \\
\hline No manuals & $9.2 \%$ & $12.4 \%$ \\
\hline Manuals & $28.5 \%$ & $15.9 \%$ \\
\hline Independent & $30.7 \%$ & $28.7 \%$ \\
\hline No manuals & $4.2 \%$ & $8.9 \%$ \\
\hline Manuals & $26.5 \%$ & $19.8 \%$ \\
\hline Total & $100.0 \%$ & $100.0 \%$ \\
\hline
\end{tabular}

Source: Own elaboration.

In the working class, the decline occurred mainly in the fraction of manual workers and in salaried workers. The increase in the intermediate class was significant, of almost fifteen percentage points between 2002 and 2018 and occurred in the professional and technical class positions and administrative personnel. The owner class maintained a reduction pattern, similar to that of the country.

The scheme of social strata, built on the basis of education and income and presented in Table 8, also shows for 2002 and 2018 a classic pyramid-type social structure. In both years, the base was made up of a broad low stratum, which, in turn, was mostly made up of the very poor low stratum. This comprised $44 \%$ of the stratified employed population in 2002 , a figure that for 2018 rose five percentage points. 
Table 8

Social strata of Guatemala. Years 2002 and 2008.

\begin{tabular}{|l|l|l|}
\hline Strata & 2002 & 2018 \\
\hline High & $\mathbf{9 . 2 \%}$ & $\mathbf{9 . 2 \%}$ \\
\hline Medium & $\mathbf{2 6 . 1 \%}$ & $\mathbf{2 0 . 4 \%}$ \\
\hline Medium high & $10.4 \%$ & $9.2 \%$ \\
\hline Medium low & $15.7 \%$ & $11.2 \%$ \\
\hline Under & $\mathbf{6 4 . 7 \%}$ & $\mathbf{7 0 . 4 \%}$ \\
\hline Poor under & $20.4 \%$ & $21.2 \%$ \\
\hline Very por under & $44.3 \%$ & $49.2 \%$ \\
\hline Total & $100.0 \%$ & $100.0 \%$ \\
\hline
\end{tabular}

Source: Own elaboration.

The middle stratum in both years had an important participation in the social structure. At least one out of every five employed persons in 2002 and 2018 belonged to the middle stratum. Within this, the majority stratum was the lower middle stratum, a situation that reflects the conditions of vulnerability, especially with regard to income, in which its members were integrated into the middle stratum. This was manifested through the reduction of almost six percentage points that the middle stratum experienced between 2002 and 2018 . This fact allows us to return to the idea raised regarding the downward process of absolute mobility, although in this case it was in the middle stratum. Likewise, the evolution of the lower and middle strata makes it possible to reinforce the idea of a static society, in this case in the upper stratum, as a characteristic of Guatemalan society.

As was done with the class scheme, graph 2 presents the Guatemalan social pyramid according to social strata. In it, Guatemalan society can be visualized as a six-step pyramid. The base step, made up of the very poor low stratum, is wide, it can be said that it was also solid because it expanded between 2002 and 2018.The second step is less wide and shows a greater difference in width with the previous one than with the previous steps. following, which are integrated with the middle and high segments. Between these the difference in width is reduced, so that in that part the pyramid becomes partially vertical. 


\section{Grph 2}

Source: Own elaboration, based on table 8 .

The analysis of the social strata of Guatemala according to geographic area, contained in table 9, reveals that the increase in the low stratum between 2002 and 2018 occurred more in the urban area. Indeed, in this area the size of the lower stratum increased five percentage points in the indicated period. The increase occurred mainly in the very poor lower stratum, originated in a reduction of a similar amount in the lower middle stratum.

In rural areas, the increase in the lower stratum was almost one percentage point and occurred in the poor stratum. The data show that this increase was partly due to the reduction of the lower middle stratum. The upper stratum registered a small increase in each of the areas.

Table 9

Social strata of Guatemala, according to geographic location.

Yers 2002 and 2018.

\begin{tabular}{|l|l|l|l|l|}
\hline \multirow{2}{*}{ Strata } & \multicolumn{2}{|l}{ Urban } & 2018 & \multicolumn{2}{l}{ Rural } & 2018 \\
\cline { 2 - 5 } & 2002 & $\mathbf{1 1 . 4 \%}$ & $\mathbf{1 . 0 \%}$ & $\mathbf{1 . 7 \%}$ \\
\hline High & $\mathbf{1 0 . 9 \%}$ & $\mathbf{2 3 . 0 \%}$ & $\mathbf{1 2 . 7 \%}$ & $\mathbf{1 1 . 1 \%}$ \\
\hline Medium & $\mathbf{2 9 . 0 \%}$ & $10.5 \%$ & $4.0 \%$ & $4.8 \%$ \\
\hline Medium high & $11.8 \%$ & $12.5 \%$ & $8.7 \%$ & $6.3 \%$ \\
\hline Under & $17.2 \%$ & $\mathbf{6 5 . 6 \%}$ & $\mathbf{8 6 . 3 \%}$ & $\mathbf{8 7 . 2 \%}$ \\
\hline Poor under & $\mathbf{6 0 . 1 \%}$ & $23.2 \%$ & $12.7 \%$ & $13.6 \%$ \\
\hline Very por under & $22.0 \%$ & $42.4 \%$ & $73.6 \%$ & $73.6 \%$ \\
\hline Total & $38.1 \%$ & $100.0 \%$ & $100.0 \%$ & $100.0 \%$ \\
\hline
\end{tabular}

When comparing the data of the strata of the urban and rural areas, the same phenomenon is observed as in the class structure, in the sense that the social pyramid of the rural area has a broader base 


\section{Analysis of results}

A first relevant aspect of the analysis of the class structure and social strata in Guatemala is its pyramidal shape, which reflects the hierarchical characteristic of Guatemalan society, as well as the inequality that this implies in access to economic resources, such as income, and social, such as authority and prestige. The wide base of the pyramid and its reduced cusp reflects that we are dealing with a society composed mainly of two classes, popular and superior to put it in terms of Touraine (1995), among which an incipient intermediate class emerges (Goldthorpe, 1993), to which, in the best of cases, one in five people of the employed population at the country level belongs to 2018 .

The second notable element is the static nature of the class and social strata structure during the period of analysis, which is an indication of a rigid and closed social stratification system (Pérez, Andrade, Bastos \& Herradora, 2003). In terms of Parkin (1978), a system with exclusionary social closure is observed, which during the study period manifested itself through the reduction, relative and absolute, of the owner class and in the stability of the upper stratum, as well as the stable participation of the working class, both urban and rural, in the total employed population in the years analyzed. Based on the data, it can be said that downward social mobility occurred at the top of the social pyramid and horizontal mobility at the base, during the study period.

Regarding the stable participation of the working class in the total employed population of the country, it can be said that this phenomenon is explained by the low social mobility in its existing educational form. A study reveals a low index of educational social mobility between 2000 and 2014, a period in which this social indicator increased from 0.30 to 0.44 . According to this study, the educational social mobility registered in that period was mostly short distance (Díaz, 2018). Based on these data, the aforementioned author affirms that in Guatemala one should talk more about educational social reproduction than educational social mobility.

Another noteworthy element of analysis is the contrast that both schemes present with regard to changes in the intermediate class or stratum. In the class scheme, elaborated on the basis of occupations, an increase in the intermediate class is observed, especially in professional class positions and administrative personnel, related to education. However, in the strata scheme, built on the basis of education and income, a reduction in the middle stratum is observed. This phenomenon is a reflection of the reduction in the returns to education evidenced in the 
study period, according to Díaz (2019), who in his research estimates a reduction of more than fifteen percentage points in the returns to education at the secondary and university levels. , between 2002 and 2018. Consequently, the aforementioned author maintains that this reduction has implications for poverty, which is evidenced by the greater probability of being in a situation of poverty that he estimated in people with secondary and university education. In the first case, said probability increased twenty percentage points between 2000 and 2014, while in the second the increase was three percentage points.

In a comparative analysis at the country level, it should be noted that studies carried out over a period of fifteen years, between 1989 and 2004, revealed an increase of thirteen percentage points in the middle strata, with a consequent reduction in the lower strata (UNDP, 2005). In contrast, even with the methodological differences, the present investigation revealed a drop, of six percentage points, in the participation of said strata, in the similar period of time analyzed up to 2018. In this regard, it must be said that in this second period there was a severe world economic crisis, which affected Guatemala, unlike the first period, between the end of the last century and the beginning of the present, in which the country registered an average annual growth of $3.6 \%$.

It is in the class structure of the urban area of Guatemala City, the country's center of economic and political power, where the greatest changes are observed, in terms of upward social mobility, from the working class to the middle class. In the capital of the country, the middle class already has a significant proportion, around four out of every ten people of the employed population. The importance of its relative weight as a social actor was evidenced in the anti-corruption demonstrations held in the country in 2015.

At the level of comparative analysis with other countries, it is observed that Guatemala has a class structure similar to other Latin American countries, such as Chile (Pérez, 2018), Colombia (Fresneda, 2017) and Mexico (Zamudio, Cosmes, Arana, Andrade, Becerril and Rodríguez, 2018), with regard to its pyramidal shape. In the cases of Chile and Colombia, there is also similarity in the stability of the participation of the working class over a period of almost two decades. In Chile this class represented almost 60\% between 1992 and 2013, while in Colombia the participation was around 65\% between 1994 and 2012.

A final analysis carried out is to contrast the class self-ascription expressed by people with the elaborated class structure. According to data from the Latinobarómetro survey for the years 2014 and 2015, out of a sample of 2,772 people, 54\% self-classified as part of the lower 
class, $44 \%$ said they belonged to the middle class and the remaining $3 \%$ to the upper class (Latinobarómetro Corporation, 2015 and 2016). In the lower class, the described percentage of self-ascription is less than the $70 \%$ obtained in the stratification elaborated in this research. The percentage of self-identification of the middle class is almost double that estimated for the middle stratum in this work. People with primary education identified themselves more as members of the lower class, while people with secondary and university education identified themselves more as members of the middle class (Díaz, 2020). One aspect to highlight is that in the results of class self-ascription, a pyramidal stratification was also obtained, although not as triangular as that estimated based on income and education, but a little wider in the middle part. This means that the interviewees tend to see themselves more as a middle class than as a lower class, in which their income and education conditions are located. This can be interpreted as a dissonance between self-ascription and class location.

\section{Conclusions}

The comparative analysis of the Guatemalan social pyramid elaborated in this work shows a static class structure at the base, between 2002 and 2018. Global mobility occurred in an exchange between the owner and intermediate classes. In the first case it was descending and in the second, ascending. This pattern was repeated in the urban and rural areas.

The base of the Guatemalan social pyramid is made up of the working class, which is mostly independent or self-employed and manual.

The intermediate class is incipient in Guatemalan society, having an urban character. This class showed a significant expansion during the years of study.

The social stratification based on income and education showed an increase in the low stratum, especially the low poor, as well as a reduction in the middle stratum, between 2002 and 2018. The increase in the low stratum was both in the urban and rural.

Self-ascription as a member of the lower class is high, as is the stratification carried out in this study, but to a lesser extent, $54 \%$ versus $70 \%$, respectively. The percentage of people who consider themselves members of the middle class is almost double that obtained in the stratification carried out. 


\section{References}

[1] Atria, R. (2004). Occupational structure, social structure and social classes. Social Policy Series, 96. Santiago, Economic Commission for Latin America and the Caribbean.

[2] Azariadis, C. and Stachuski, J. (2005). Poverty traps. In: P. Aghion and S. Durlauf, edits.

[3] Handbook of economic growth. London: Elsevier, pp. 295-384.

[4] Bank of Guatemala. (2002). National directory of companies and their premises 2002. Guatemala: Proname.

[5] Bank of Guatemala. (2013). National directory of companies and their premises 2013. http://www.banguat.gob.gt/sites/default/files/banguat/Publica/DINEL/Informe_DINEL_ 2013.pdf

[6] World Bank. (February 15, 2021). Databank. https://datos.bancomundial.org/

[7] Cortés, F. and Escobar, A. (2005). Intergenerational social mobility in urban Mexico. CEPAL Review, (83), 149-167.

[8] Bordieu, P. (2001). Power, right and social classes. (Trans. J. Bernuz). Madrid: Desclée de Brouwer.

[9] Latinobarómetro Corporation. Report 2015. https://www.latinobarometro.org/lat.jsp

[10] Latinobarómetro Corporation. Report 2016. https://www.latinobarometro.org/lat.jsp

[11] Dalle, P. (2012). Recent changes in social stratification in Argentina (2003-2011). Inflections and emerging dynamics of social mobility. Arguments. Journal of social criticism, (14), 77-114.

[12] Dahrendorf, R. (1966). Social classes and their conflict in industrial society. Madrid: Rialp.

[13] Díaz, G. (2012). Stratification and social mobility in Guatemala. CEPAL Review (107), $31-49$.

[14] Díaz, G. (2018). Poverty and educational social mobility in Guatemala. The social elevator walks slowly. Podium, 33, 45-54.

[15] Díaz, G. (2019). The Poverty Club in Latin America. The Guatemala case. Bet. Revista de Ciencias $\quad$ Sociales, $\quad 83, \quad 138-152$, http://apostadigital.com/revistav3/hemeroteca/godiaz.pdf

[16] Díaz, G. (2020). Educational social mobility in Guatemala: The social elevator walks slowly. International Journal of Humanities Social Sciences and Education, (7), 8, 71-79. 
[17] Erikson, R. and Goldthorpe, J. (1993). The constant flux: A stury of class mobility in industrial societies. Oxford: Claredon Press.

[18] Espinosa, V., Barozet, M. and Méndez, M. (2013). Stratification and social mobility under a neoliberal model: The case of Chile. Revista Lavboratorio, (25), 14, 169-191.

[19] Ferreira, F., Messina, J., Rrigolini, J., López, L., Lugo, M. and Vakis, R. (2013). Economic mobility and the growth of the middle class in Latin America. Washington: World Bank.

[20] Fresneda, O. (2017). Evolution of the class structure in Colombia, 1983-2010. Have the middle classes grown? Society and economy. (33), 205-236.

[21] Statistics National Institute. (2019). XI National Population Census and VI of Housing 2002. https://www.ine.gob.gt/ine/censo-2002/

[22] Statistics National Institute. (2003). National Survey of Employment and Income. 2002. https://www.ine.gob.gt/index.php/encuestas/empleo-e-ingresos

[23] Statistics National Institute. (2018). National Survey of Employment and Income. 2018. https://www.ine.gob.gt/index.php/encuestas/empleo-e-ingresos

[24] Statistics National Institute. (2019). XII National Population Census and VII of Housing 2018. https://www.censopoblacion.gt/descarga

[25] Kerbo, H. (2003). Social stratification and inequality. Madrid: McGrawHill.

[26] Kessler, G. and Espinoza, V. (2003). Social mobility and occupational trajectories in Argentina: Ruptures and some paradoxes in the case of Buenos Aires. Social Policy Series, 66. Santiago, Economic Commission for Latin America and the Caribbean.

[27] Lenski, G. (1969). Power and privilege. Theory of social stratification. Buenos Aires: Paidós.

[28] Marx, C. (1973). Capital. Critique of Political Economy. Mexico: Economic Culture Fund.

[29] Marx, C. and Engels, F. (1970). Manifesto of the communist party and other political writings. Mexico: Grijalbo.

[30] Marhino, L. and Quiroz, V. (2018). Social stratification: A multidimensional methodological proposal for the northern subregion of Latin America and the Caribbean. Mexico, Economic Commission for Latin America and the Caribbean.

[31] Ministry of Education. (2019). Statistical Yearbook of Education in Guatemala. Guatemala: Author. 
[32] Parkin, F. (1978). Political order and class inequalities. Social stratification of capitalist and communist societies. Madrid: Debate.

[33] Pérez, P. (2018). Social classes, economic sectors and changes in the Chilean social structure between 1992 and 2013. CEPAL Review (126), 171-191.

[34] Pérez, J., Andrade, K., Bastos, S. and Herradora, M. (2003). The social order in the face of globalization. Stratifying processes in Central America during the nineties. Social Policy Series, 80. Santiago, Economic Commission for Latin America and the Caribbean.

[35] UNDP. (2005). Ethnic-cultural diversity: Citizenship in a plural state: National Human Development Report 2005. Guatemala: Author.

[36] Portes, A. and Hoffman, K. (2003). Class structures in Latin America: Composition and changes during the neoliberal era. Social Policies Series, 68. Santiago, Economic Commission. 